\title{
Discriminação de rendas entre a União e os Estados
}

\author{
Preleção inaugural dos cursos em 1933 \\ J. J. Cardozo de Mello Neto
}

Não há federação, digna dêsse nome, onde não fique garantida pela Constituïção, a autonomia dos Estados federados.

A autonomia é "a direção própria daquilo que lhe é próprio".

Mas, êsse direito de desenvolver todas as atividades $€$ serviços próprios, não passará de mera declaração poética, impossivel de ser concretizada, se não vier acompanhada da 'efetiva garantia dos meios econômicos e financeiros capazes de a assegurar, em toda sua plenitude.

Ora, tal só se consegue por uma inteligente discriminação de rendas, em virtude da qual tanto a União, representante da soberania, como os estados, autônomos, possam viver dentro da órbita que lhes é traçada, sem que um venha a invadir a esfera de ação peculiar ao outro.

Como deve proceder o legislador constituinte no Brasil, para que seja alcançado êsse desideratum - base e funda- 
mento do regime federativo, único dentro do qual podemos e queremos viver?

Cinco são os sistemas de classificação de rendas, dentre as quais havemos de escolher o nosso:

1..$^{\circ}$ A União e os estados vão. basear os seus recursos nas mesmas fontes, sem qualquer discriminação entre impostos federais e estaduais;

2. ${ }^{\circ}$ Aos Estados compete concorrer com uma quota fixa, ou proporcional, para fazer face às despesas da União, que por si nada arrecada;

3.') Os Estados reservam para si certas fontes de receita, deixando à União todas as outras;

4. ) A União reserva para si certas fontes de receita, deixando as demais aos Estados; e, finalmente,

5.') A União reserva para si certas fontes de receita; aos Estados, por sua vez, cabem fontes de receita privativas; todo poder de tributação não especificado fica concorrentemente pertencendo à União e aos Estados.

Combatendo os três primeiros sistemas já tivemos ocasião de mostrar, há 15 anos (Discriminação de rendas entre a União e os Estados, tese de concurso), que:

Não discriminando os impostos gerais dos provinciais, no Pacto Constitucional, êste sistema deixa inteiramente à discreção das legislaturas ordinárias, da União e dos Estados a escolha das respetivas fontes de receita.

À inteligência dos menos versados na Ciência econômica, saltará logo a falha de tal solução.

Sem outro guia ou critério a não ser o próprio arbitrio, o centro e as províncias escolherão, cada qual para si, as mais produtivas fontes de receita: a lei ordinária federal taxará a importação e a exportação, a transmissão dos imóveis, o comércio, etc., no humano intuito de criar rendas que 
possam cobrir largamente as suas despesas, não só as necessárias aos fins do Estado, como as voluptuárias. A mesma cousa farão os Estados federados. A conseqüência será uma supertributação insuportável para os contribuintes, obrigados a pagar, pelos mesmos serviços, impostos duplos, - à Ułnião e aos Estados.

O sistema relega o axioma de Ciência das Finanças, segundo o qual - impostos há de natureza exclusivamente federal, outros de natureza exclusivamente estadual, e outros, ainda, de natureza exclusivamente local. - Permitindo que os Estados taxem, por exemplo, a importação dos produtos (imposto por excelência federal, pois sua matéria pode ser, e em regra é, objeto de tratados ou convênios com países estrangeiros, no sentido da obtenção da reciprocidade de favores), o sistema vai até afetar o direito internacional, com a invasão, pelos Estados federados, da órbita reservada à soberania, que reside ùnicamente no Estado federal.

Por igual, facultando à União tributar a exportação dos produtos (imposto eminentemente estadual), o sistema coloca em injusta inferioridade os Estados. Estes, quanto mais trabalhem, quanto mais produzam, tanto mais sangrados se verão nas suas riquezas para atender-se às necessidades da União, e de tanto menos disporão para poderem exercer ùtilmente a sua atividade jurídica e social.

Inteiramente condenado pela Ciência, o sistema da competência cumulativa da União e dos Estados na imposição de todos os tributos, não teve na primeira Constituinte Republicana voz autorizada que o preconizasse.

O mesmo não se pode dizer do segundo sistema, que a muitos se afigurára realizar o ideal em matéria de federação" (Julio de Castilho, Anais da Constituinte, I, 183).

Aliás, contra êle milita o mesmo argumento tirado do fato de ficarem por tal modo pertencendo aos Estados (e, no caso, exclusivamente a êstes) impostos por natureza federais, como o de importação.

E a par dessa, outras razões demonstram à evidência a precariedade da solução aventada. 
O sistema de que se trata, posterga de maneira flagrante os direitos da União, posta por êle na dependência completa dos Estados quanto ao preenchimento de uma de suas funções essenciais - a organização de orçamentos, de despesa e receita.

Uma das regras da economia pública é que devem primeiro fixar-se as despesas necessárias ao preenchimento dos fins e encargos do Estado, para depois, e na medida delas, calcular-se o quantum a arrecadar sôbre os haveres comuns das diferentes classes da Nação.

Aplicando a regra ao caso:

O Congresso Federal organiza o orçamento de sua despesa, a qual, rètamente calculada, se justifica por si mesma como uma necessidade da própria Nação. Em seguida, passa a organizar o orçamento de receita.

Que base terá para isso, entretanto, se não é a União que tributa, se ela está adstrita a uma percentagem da renda dos Estados, receita variável, incerta, dependente exclusivamente da soma total das tributações estaduais? 0 resultado será que, muita vez, a soma recebida dos Estados não dará para equilibrar o orçamento federal. E para esta hipótese, perfeitamente realizável, o sistema que vimos combatendo não tem solução.

Há mais, ainda, a considerar.

Os Estados, principalmente os Estados modernos, à vista da grande soma de atribuïções que lhes vão cada vez mais ficando a cargo, não se podem limitar à renda proveniente dos impostos, e à dos estabelecimentos e instituïcões industriais, - carecem recorrer ao crédito, "ao qual muitas nações devem a sua própria independência politica, e outras uma parte considerável dos progressos de todo gênero que têm podido realizar (Amaro Cavalcanti).

Ora, nos países novos, faltos de capitais indígenas, o empréstimo é, as mais das vezes, externo. A Nação precisa, em tais condições, dar a conhecer ao credor os recursos de que dispõe para honrar o compromisso tomado. Mas, como 
poderá fazê-lo quem por si não tem o direito de lançar um imposto destinado ao serviço da dívida contraída?

Os partidários do terceiro sistema por fôrça do qual os Estados ficam circunscritos a determinadas fontes de receita, taxativamente enumeradas, deixando à União todas as outras, são em reduzidissimo número. São os adéptos da absoluta centralização administrativa, para os quais ao centro deve caber, não só o exercício da atividade jurídica do Estado (a manutenção da ordem, a distribuïcão da Justiça, e a defesa do território), como o preenchimento de sua função social promotora do progresso nas suas variadas fórmas. Os Estados são, nêste caso, méras circunscrições administrativas, sem autonomia; órgãos secundários de um só corpo dirigente - o centro.

$\mathrm{E}$ ai está por que, errada mas lògicamente, êles requerem para a Uniâo a totalidade dos impostos, reservadas às províncias algumas poucas fontes de receita, a cuja produção teriam de submeter as suas necessidades.

A só exposição do sistema, é bem de vêr, fá-lo repelir desde logo como anti-científico. Os seus sustentadores se obstinam em desconhecer que à descentralização administrativa, à autonomia dos Estados, à federação, deve o Estadomoderno a sua formidável, mas benéfica, transformação.

Restam em campo os dois últimos temas, quarto e quinto. O último foi o vencedor na primeira Constituinte Republicana - é o dentro de cujas linhas temos vivido desde 1889. E' o que nós há 15 anos, entendiamos ser o preferivel.

Hoje, porém, temos de nos curvar diante dos fatos, e reconhecer os vícios e defeitos que o inquinam, tão reais e palpáveis são êles. Eis por que nos inclinamos para o outro - aquele pelo qual - a União reservará para si certas fontes de renda taxativamente enumeradas na Constituïcão ficando as restantes abandonadas aos Estados. As objeções levantadas contra o sistema desaparecem, se dermos à União a válvula de segurança da taxação da renda dos Estados, em 
caso de insuficiência manifesta das fontes de renda a ela reservadas.

\section{A DISCRIMINAÇÃO CONSTITUCIONAL}

E' a seguinte:

A) Pertencem exclusivamente à União:

$10^{\circ}$ - Os impostos de importação de gêneros de procedência estrangeira (art. $7 .^{\circ}$ ); revertendo para os cofres federais os que forem criados pelos Estados sôbre os mesmos gêneros, quando destinados a consumo no seu território (art. $90^{\circ} \S 3 .^{\circ}$ );

$2 .^{\circ}$ - Os direitos de entrada e saída de navios; sendo livre o comércio de cabotagem às mercadorias nacionais, bem como às estrangeiras que já tenham pago imposto de importação (art. 7. $)$;

3. - As taxas de sêlo, exceto sôbre os atos emanados dos Govêrnos dos Estados, e sôbre os negócios de economia dêstes (art. 7.0);

$4 .^{\circ}$ - As taxas de correios e telégrafos federais (art. $7 .^{\circ}$ ).

B) Pertencem exclusivamente aos Estados:

$10^{\circ}$ - Os impostos de exportação de mercadorias produzidas no seu território (art. $90^{\circ} \mathrm{n} .1$ ); não lhes sendo licito tributar a exportação de produtos de outros Estados, quando em simples trânsito (art. $\left.9 .^{\circ} \S 3 .^{\circ}\right)$;

$20^{\circ}$ - Os impostos sôbre imoveis rurais e urbanos (art. 9. ${ }^{\circ}$ n. 2);

$3 .^{\circ}$ - Os impostos sôbre transmissão de propriedade (art. $9^{\circ}$ n. 3); 
$4^{\circ}$ - Os impostos de indústrias e profissões (art. $9 .^{\circ}$, n. 4$)$;

$5 .^{\circ}$ - As taxas de sêlo sôbre os atos emanados dos respetivos govêrnos e sôbre os negócios de sua economia (art. $90^{\circ} \S 10^{\circ}$ );

$6 .^{\circ}$ - As taxas de seus correios e telégrafos (art. $9 .^{\circ} \S 1 .^{\circ}$, n. 2 ).

C) Pertencem, indistintamente, cumulativamente ou não, à União e aos Estados, quaisquer outras fontes de receita não enumeradas entre as de competência privativa (art. 12), excluido o imposto de trânsito, que foi expressamente abolido (art. $11 \S 10^{\circ}$ ).

D) Dos impostos deixados aos Estados, têm êstes de atribuir alguns aos municipios, para lhes assegurarem a autonomia (art. 68); podendo proceder-se a uma discriminação, ou estabelecer-se a competência tributária cumulativa (arts. 12 e 63).

E) A União só pode criar impostos uniformes para todo o território nacional (art. $70^{\circ} \S 20^{\circ}$ ). Do mesmo modo, os Estados só podem criar impostos uniformes para todo o respetivo território (art. 63).

F) Os Estados não pódem tributar bens e rendas federais, ou serviços a cargo da União, e vice-versa (art. 10).

\section{FUNDAMENTO DA DISCRIMINAÇÃO CONSTITUCIONAL:}

Pude ser assim resumido:

"Tanto a União como os Estados, têm cada qual sua missão a cumprir dentro da Federação, missões distintas uma da outra, e tão essenciais uma como a outra. Não podem, pois, os Estados, como não pode a União, ficar adstritos a determinadas fontes de receita; uns e outros carecem de plena liberdade de ação para o preenchimento dos fins do Estado. E isto só se consegue, consignando à União os 
impostos de natureza federal, e aos Estados os de natureza local; deixada a êstes e àquela a faculdade de, concorrentemente, criarem outras fontes de receita."

$\mathrm{E}$, se assim é em teoria, "não há motivo para recear quaisquer inconvenientes, na prática".

“ $E$ ' natural e deve esperar-se que venha a prevalecer, na concorrência de que se trata, o ponderado conselho de Hamilton: "A União deve se abster inteiramente daqueles objetos a que os Estados estejam mais dispostos a recorrer" (J. Barbalho).

Examinemos o fundamento, invertendo-lhe a ordem.

De duas uma, ou "a União se abstem daqueles objétos a que os Estados estejam mais dispostos a recorrer", e então se enclausura dentro dos impostos privativos, não havendo necessidade de ficar estabelecido poder concorrente; ou a União faz concorrência aos Estados, tributando os mesmos objetos, as mesmas atividades por êstes tributados, e nêste caso temos a bitributação.

Ora, a tributação, por entidades diferentes, dos mesmos objetos ou atividades, é um mal de conseqüências à vezes imprevisiveis.

- E' o maior mal dos regimes tributários, tanto para o fisco como para o contribuinte.

Na verdade: quando o poder público lança um imposto, precisa contar com a capacidade produtiva do contribuinte. A verificação do grau de absorção, pela coletividade, do quantum a arrecadar, ha-de ser sempre o tormento dos financistas. Se a imposição fere o lucro que legitimamente o contibuinte deve esperar do desenvolvimento de sua atividade, se entorpece os negócios em curso, desanimando os futuros, ela peca por anti-econômica. - A receita arrecadada não corresponderá jamais à orçada.

Ora, se é assim dificil ao poder público, conhecer o momento de saturação do contribuinte, sabido, de ante-mão, qual o quantum que vai dêle exigir, em relação a cada ramo de atividade, impossivel será fazer qualquer cálculo, estabelecer seja qual for a pressão orçamentária, tendo ao seu 
lado outro poder, com igual faculdade de tributar êsse mesmo contribuinte em idêntico ramo de atividade taxada. A saturação é inevitável, e a arrecadação desapontará a ambos os poderes concorrentes.

E, entre Scyla e Carybides, o contribuinte oscila, ao léu, Foi o que se deu entre nós.

O que aos constituintes parecia natural, e deveriam esperar que se desse, realizou-se pelo avésso.

Em vez de limitar-se a procurar fontes de renda na tributação que lhe ficou privativamente reservada (e vamos demonstrar que esta seria suficiente às suas necessidades) a União não só foi buscar outras daqueles objetos "a que os Estados estariam naturalmente dispostos a recorrer", como também, e abusivamente muita vez, invadiu a própria esfera de ação privativa dos Estados.

$\mathrm{E}$ o resultado é conhecido: a bitributação dos mesmos objetos, pela União e pelos Estados, com todas as danosas conseqüéncias 'próprias do defeituoso regime tributário constitucional.

E' certo que a União tem uma missão essencial a cumprir dentro da federação; é menos certo, porém, que para cumpri-la necessite ela de fazer imposições tributárias concorrentemente com os Estados.

A esfera de ação da União é limitada. Seus poderes são esplícitos; só os Estados têm poderes implícitos. E' um - princípio consagrado na Constituïção de 1891, que não pode ser alterado sem sacrifício do regime federativo.

Se, pois, está predeterminada a esfera de ação da União, se ficam conhecidos os serviços que a ela competem, a União não pode, nem deve, realizar obras, nem desenvolver atividades pertinentes aos Estados federados, porque não predeterminar a sua esfera de ação impositiva?

Porque, objetam-nos, "é a União que representa a soberania, é ela que faz a guerra e socorre os Estados em caso de calamidade pública. Daí o seu incontrastável direito de, nestes casos pelo menos, verificada a escassez da renda proveniente dos impostos que se lhe houvessem reservado, 
buscar em outras fontes o suficiente para provar a tais necessidades"

A objeção impressiona, mas não convence.

Nos casos apontados, bastará majorar os impostos federais para obter-se o necessário ao pagamento das despesas extraordinárias, se não se quiser buscar o recurso no empréstimo, interno ou externo, o que, aliás, é a solução natural.

Do que se conclúi dever-se adotar no Pacto Constitucional o sistema pelo qual fiquem reservados à União determinadas fontes de receita, deixando-se as demais aos Estados.

Quais, porém, essas fontes de receita, que devem caber à União?

a) 0 imposto sôbre a renda;

b) 0 imposto sôbre a importação de procedência estrangeira;

c) 0 imposto de consumo;

d) Os direitos relativos à entrada, saída e estada de navios, sendo livre o comércio de cabotagem às mercadorias nacionais, bem como às estrangeiras, que já tenham pago imposto de importação;

e) As taxas de sêlo, salvo quanto aos atos emanados dos Estados e negócios da economia dêstes;

f) As taxas de correios e telégrafos.

Daí se mostra que, além dos impostos e taxas ora privativos da União, ainda the atribuimos o imposto sôbre a renda e o de consumo, criados por leis ordinárias, e que já fazem parte dos orçamentos federais. - São exatamente os impostos dentro de cujo âmbito a União tem visto aumentar progressivamente suas rendas e podido custear serviços e realizar obras, muitas mesmo não da sua competên- 
cia, e sïm da dos Estados federados. Exemplificativamente: - os serviços do Ministério da Agricultura, e, no da Viação, o das estradas de ferro, que não são de natureza estratégica.

Se assim é, tudo impõe que se lhe retire a faculdade de concorrer com os Estados federados, perturbando-lhes a economia.

Estes, sim, é que carecem ter uma ampla esfera de ação tributária. Porque - é aos Estados federados que deve caber, na sua integridade, ou quasi, o exercício da atividade social do Estado moderno, a sua ação impulsionadora ou promotora do progresso, em relação à cultura como à saúde pública; à emigração como à imigração; à produção como à distribuïção e consumo da riqueza; à assistência pública como ao desenvolvimento numérico das populações. A função dos Estados federados é, assim, tão extensa e elástica, que a ela devem corresponder meios igualmente elásticos para o preenchimento de seus fins.

Dentro dos limites tributários que lhe assinalamos, a União poderá largamente cumprir sua missão, que normalmente se resume na manutenção da ordem jurídica interna, e na defesa do território contra o inimigo externo.

Clamam alguns (e a grita vem de longe) que a discriminação de rendas, precisa ser modificada no sentido do aumento das fontes federais. Para êsses, a União foi lesada na partilha.

Nada menos verdadeiro.

Já em 1896, o Cons..$^{\circ}$ Rodrigues Alves ieve ocasião de aludir “à crença, hàbilmente explorada de que, na partilha das rendas, ficára (a União) desprovida de recursos, para acorrer às suas despesas", afirmando a improcedência dessa proposição.

O aumento formidável da receita federal durante quarenta anos de República evidencia que não devem ser levados à conta da escassez de fontes de rendas, os deficits federais. Éstes têm múltiplas causas, não sendo a maior 
a já assinalada: - a extensão dada pela União a serviços, que em sua maioria competem, nas federações, aos Estados federados.

Porque a autonomia dos Estados não lhes dá sòmente direitos, mas acarreta-lhes ônus correspondentes. Só pugna legitimamente por sua autonomia quem tem recursos econômicos próprios para a tornar efetiva.

O fato, porém, é que a dívida nacional existe, e precisa ser honrada.

Daí a providência que lembramos:

"Em caso de insuficiência manifesta das fontes de receita da União para o serviço da dívida externa do Brasil, poderá a renda dos Estados ser taxada em igual percentagem para cada um dêstes"

Assim como a União não deve invadir a esfera tributária dos Estados, êstes não devem usar dos impostos de natureza municipal, que; todos, carecem ficar garantindo a execução dos serviços municipais.

$\mathrm{O}$ abuso do legislador paulista, incorporando á receita estadual o imposto predial - eminentemente municipal - mostra a necessidade de ser especificada, na Constituïção, a esféra de ação tributária do município.

Eis porque sugerimos a seguinte disposição:

"Constituirão fontes de receita dos municípios o imposto predial, o imposto de indústrias e profissões, e todas as taxas relativas a serviços públicos de natureza municipal".

Aquí entrámos defendendo a discriminação de rendas constitucional. A observação persistente dos fatos nos fez mudar de rumo. 
A atual discriminação de rendas só poderia permanecer se "a União se houvesse sempre abstido daqueles objetos a que os Estados estivessem mais dispostos a recorrer"

Os fatos demonstraram eloqüentemente o contrário.

E' preciso, pois, circunscrevê-la a fontes de renda taxativamente enumeradas, dentro das quais desenvolverá os serviços que lhe tocam.

Para os casos de salvação pública, e só para êsses, uma percentagem arrecadada das receitas estaduais resolverá a situação, sem prejuizos da economia dos Estados, que precisa ficar resguardada. 